\title{
PENGETAHUAN KELUARGA TENTANG FAKTOR RESIKO DAN GEJALA AWAL STROKE DI RSUD.H. BOEJASIN PELAIHARI
}

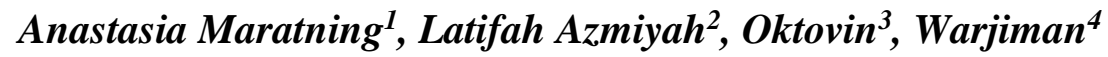 \\ ${ }^{1,3,4}$ Dosen Sekolah Tinggi Ilmu Kesehatan Suaka Insan Banjarmasin, \\ ${ }^{2}$ Perawat RSUD H. Boejasin Pelaihari. \\ Email: anas.maratning@gmail.com
}

\begin{abstract}
Abstrack
Stroke today should be viewed as a medical emergency in addition to a heart attack. Stoke is the number one cause of disability and number three death in the world. Early and prompt treatment of stroke can reduce mortality and the risk of disability. Family knowledge about stroke is needed so that it affects the rapid treatment of stroke. Lack of family knowledge about stroke is one of the causes of the high number of patients whose treatment has passed the golden period so that it affects the severity of stroke. This study was aims to determine the description of family knowledge about risk factors and early symptoms of stroke in hospitals. H. Boejasin Pelaihari. This research was a type of quantitative descriptive research. The population was the family of stroke patients in the stroke room with a sample of 30 respondents. The sampling technique used was purposive sampling. The instrument was a questionnaire about the level of knowledge of the patient's family. The results showed the level of family knowledge about risk factors that can cause stroke with good category of $13.33 \%$, adequate category $33.33 \%$, and less category $53.34 \%$. While the level of family knowledge about the early symptoms of stroke with a good category of 43.33\%, 50\% sufficient category and $6.67 \%$ less category. The level of family knowledge about the risk factors that cause stroke was obtained in the category of less and the level of family knowledge about the early symptoms of stroke in hospitals. H. Boejasin Pelaihari obtained results with sufficient category. This study concluded family knowledge about risk factors and early symptoms of stroke was still lacking.
\end{abstract}

Keywords: Family, Family knowledge, Stroke.

\section{Abstrak}

Stroke saat ini harus dipandang sebagai kedaruratan medis selain serangan jantung. Stoke menjadi salah satu penyebab kecacatan nomor satu dan kematian nomor tiga di dunia. Penanganan awal stroke yang cepat dan tepat dapat mengurangi angka kematian dan resiko kecacatan. Pengetahuan keluarga tentang stroke sangat diperlukan sehingga berpengaruh terhadap penanganan cepat stroke. Kurangnya pengetahuan keluarga tentang stroke yang menjadi salah satu penyebab tingginya jumlah pasien yang penanganannya telah melewati masa golden periode sehingga mempengaruhi tingkat keparahan stroke. Penelitian ini bertujuan untuk mengetahui gambaran pengetahuan keluarga tentang faktor resiko dan gejala awal stroke di RSUD. H. Boejasin Pelaihari. Jenis penelitian deskriptif kuantitatif. Populasi yang digunakan adalah keluarga pasien stroke diruang stroke dengan sampel 30 responden. Teknik sampling yang digunakan purposive sampling. Instrumen berupa kuesioner tentang tingkat pengetahuan keluarga pasien. Hasil penelitian menunjukkan tingkat pengetahuan keluarga tentang faktor resiko yang dapat menyebabkan stroke dengan katagori baik sebesar 13,33\%, katagori cukup $33,33 \%$, dan katagori kurang 53,34\%. Sedangkan tingkat pengetahuan keluarga tentang gejala-gejala awal stroke dengan katagori baik sebesar 43,33\%, katagori cukup 50\% dan dengan katagori kurang 6,67\%. Tingkat pengetahuan keluarga tentang faktor resiko penyebab stroke diperoleh hasil dengan katagori kurang dan tingkat pengetahuan keluarga tentang gejala awal stroke di RSUD. H. Boejasin Pelaihari diperoleh hasil dengan kategori cukup. Penelitian ini menyimpulkan pengetahuan keluarga tentang faktor resiko dan gejala awal stroke di RSUD. H. Boejasin Pelaihari yang masih kurang.

Kata Kunci: Keluarga, Pengetahuan keluarga, Stroke.

\section{Pendahuluan}

Stroke saat ini harus dipandang sebagai kedaruratan medis selain serangan jantung. Stroke menjadi salah satu penyebab kecacatan nomor satu dan kematian nomor tiga di dunia setelah penyakit jantung dan kanker baik dinegara maju maupun negara berkembang (Indonesia,
2013). Keterlambatan untuk mendapatkan pertolongan medis dapat meningkatkan jumlah kematian dan kecacatan akibat stroke. Data Organisasi Kesehatan Dunia (WHO) tahun 2016 menunjukkan, stroke menempati peringkat kedua sebagai penyakit tidak menular penyebab kematian. Stroke juga menjadi peringkat ketiga penyebab utama kecacatan di seluruh 
dunia. Hal ini mengakibatkan sel-sel otak mengalami kekurangan oksigen serta energi dan menyebabkan kerusakan otak permanen yang mengakibatkan kecacatan sampai kematian dini (Depkes RI, 2013).

Provinsi Kalimantan Selatan (Kalsel) sendiri mengalami peningkatan angka kejadian stroke yang cukup signifikan. RISKESDAS (2018) mengkategorikan Kalsel sebagai provinsi tertinggi ke- 6 angka kejadian stroke dari seluruh provinsi yang ada di Indonesia, dan mencapai angka 12,7 kejadian per mil. Salah satu kabupaten di provinsi Kalsel yaitu kabupaten Tanah laut memiliki angka kejadian stroke selama 3 tahun teakhir, 2017 mencapai 262 kasus, tahun 2018 meningkat sebanyak 348 kasus, dan pada tahun 2019 sebanyak 189 kasus (DINKES Kab. Tanah Laut, 2020).

Peningkatan angka kejadian stroke ini sangat memprihatinkan karena dengan tingginya angka kejadian stroke maka angka penderita stroke yang sembuh dengan kecacatan juga terus bertambah (Oktovin, Nurachman, dan Syrafwani, 2020). Sekitar 50\% pasien pasca stroke mengalami kehilangan fungsi alat gerak partial maupun komplit, 30\% tidak mampu berjalan tanpa bantuan, $46 \%$ mengalami gangguan kognitif, 26\% mengalami ketergantungan dalam melakukan aktifitas sehari-hari, 35\% mengalami gejala depresi, dan $19 \%$ afasia (Go, A. S., Mozaffarian, et all 2013). Pada tahun 2018, RSUD. H. BOEJASIN Pelaihari sudah merawat 346 pasien stroke, tahun 2019 meningkat menjadi 418 pasien stroke. Jumlah pasien rawat inap sendiri pada ruang Stroke RSUD. H. BOEJASIN Pelaihari yang mengalami stroke dari bulan Juni sampai bulan September 2020 tercatat sebanyak 86 orang. Hasil studi pendahuluan selama 3 bulan terakhir Juni-Agustus 2020, sebanyak 8 orang pasien $(11,6 \%)$ dengan deficit neurologis ringan (skor $\leq 5$ ), 37 orang pasien (43\%) deficit neurologis sedang (skor 6-14), 22 orang pasien $(25,6 \%)$ dengan deficit neurologis berat (skor 15-24), dan 17 orang pasien (19,8\%) dengan deficit neurologi sangat berat (skor > 24). Pengkajian tingkat keparahan ini dihitung berdasarkan form National Institute Health Stroke Scale (NIHSS) yang digunakan diruang stroke RSUD. H. BOEJASIN Pelaihari. Skala NIHSS merupakan instrument untuk menilai gangguan neurologis. Kecepatan penilaian ini yang merupakan tindakan dasar menangani kasus stroke (Hudak et al. 2012). Semakin tinggi nilai NIHSS pada pasien stroke berarti semakin berat derajad keparahanya (Harding and bridgewetwr, 2010).

Tingginya jumlah penderita stroke yang dirawat di RSUD. H. BOEJASIN Pelaihari menunjukan tingginya keparahan kondisi pasien stroke yang mendapatkan perawatan. Seperti yang diketahui stroke juga mengakibatkan gangguan pada seluruh fungsi kehidupan penderita (Goldszmidt \& Caplan,2013). Gangguan yang sering terjadi pada penderita stroke seperti gangguan saat berkomunikasi, gangguan dalam mengonsumsi makanan, disfungsi seksual, keterbatasan dalam perawatan diri sendiri, bermasalahnya kepekaan panca indra dan rasa nyeri, serta gangguan memori, mood dan pola tidur (Arum, 2015). Keparahan ini juga tergantung pada berat ringannya serangan dan lokasi kerusakan sel pada otak (Irfan, 2012). Akan tetapi, salah satu kunci penting dalam mengurangi kematian dan meminimalkan kerusakan otak yang ditimbulkan oleh stroke adalah dengan memberikan penanganan yang cepat dan tepat (Widi, 2013).

Ketepatan penanganan sangat berhubungan erat dengan golden periode yaitu penanganan stroke adalah \pm 3 jam, artinya dalam 3 jam awal setelah mendapatkan serangan stroke, pasien harus segera mendapatkan terapi secara komprehensif dan optimal dari tim gawat darurat rumah sakit untuk mendapatkan hasil pengobatan yang optimal (Morton. 2012). Akan tetapi, di Indonesia keterlambatan penanganan pasien stroke sesaat setelah terjadi serangan stroke sering terjadi (Wirawan \& Putra, 2013). Temuan penelitian yang dilakukan oleh Ratnawardani, Wasisto \& Safitri (2018) tentang pengalaman keluarga dalam penanganan serangan pertama pada pasien stroke di Puskesmas Harapan Raya menunjukkan bahwa semua responden mengungkapkan tidak mengetahui cara penanganan serangan pertama stroke secara pasti. Penelitian ini diperkuat dengan hasil penelitian yang telah dilakukan oleh Hariyanti, Tita, et al. (2015) pada pasien stroke, yang menunjukkan bahwa dari 101 responden pasien stroke, sebanyak 58 orang $(57,4 \%)$ memiliki keluhan lemah separuh badan, sedangkan dengan keluhan kesemutan sebanyak 15 orang (15\%), keluhan tidak bisa bicara (afasia) sebanyak 3 orang (2,9\%), sedangkan dengan keluhan bicara tidak jelas sebanyak 7 orang $(6,9 \%)$, dan sisanya dengan keluhan disartria sebanyak 18 orang $(17,8 \%)$. Hasil penelitian tersebut tidak menyebutkan wajah mencong sebagai bentuk health seeking behavior pada penyakit stroke. Dalam penelitian ini keluarga pasien tidak banyak yang melakukan pengamatan terhadap wajah mencong karena lebih fokus pada kelumpuhan dan kesulitan bicara pasien dibandingkan meminta pasien untuk tersenyum sebagai deteksi terhadap adanya ketidaksimetrisan pada wajah. Perlakuan membaringkan pasien dengan posisi kepala lebih tinggi juga kurang banyak dilakukan karena kurangnya informasi tentang penanganan awal stroke ketika di rumah. Pemberian posisi kepala lebih tinggi pada pasien stroke akan memudahkan aliran balik vena pada cerebral yang menuju ke jantung.

Uraian diatas juga sama dengan hasil temuan studi pendahuluan yang dilakukan oleh peneliti dengan mewawancarai 5 anggota keluarga, dan penderita stroke 
yang berbeda yang dirawat di ruang stroke RSUD. H. BOEJASIN Pelaihari, $80 \%$ dari mereka menjawab tidak tahu tanda dan gejala awal stroke sehingga setelah mengalami serangan stroke lebih dari tiga jam baru diantar ke fasilitas kesehatan. Oleh sebab itu, keluarga sempat menunda membawa keluarganya ke rumah sakit untuk mendapatkan perawatan. Mereka merasa gejala yang dirasakan merupakan hal yang biasa sehingga mereka tetap melakukan aktivitas seperti biasanya.

\section{Metode penelitian}

Jenis penelitian ini adalah deskriptif dengan rancangan penelitian kuantitatif. Penelitian ini biasanya bertolak dari suatu teori yang kemudian diteliti, dihasilkan data, dibahas dan diambil kesimpulan (Notoatmodjo, 2010). Sampel pada penelitian ini adalah keluarga pasien stroke diruang stroke RSUD. H. BOEJASIN Pelaihari. Teknik pengampilan sampel yang digunakan adalah purposive samplin $g$ dengan menggunakan kriteria inklusi dan ekslusi. Sampel dalam penelitian ini sebanyak 30 responden. Alat ukur penelitian ini adalah kuesioner. Pertanyaan yang disediakan bersifat favorable dan unfavorable dengan menggunakan skala ordinal dan diukur dengan menggunakan Guttman Scale yang merupakan skala yang bersifat tegas dan konsisten. Uji validitas menggunakan korelasi point biserial dan Perhitungan reliabilitas instrument pada penelitian ini memiliki nilai Cronbach Alpha $\geq 0,50$.

\section{Hasil Penelitian}

\section{a. Karakteristik Responden}

Karakteristik responden yang ikut serta dalam penelitian ini ditunjukkan dalam tabel di bawah ini:

Tabel 1.1. Karakteristik Responden dilihat dari Usia, Jenis Kelamin dan Tingkat Pendidikan

\begin{tabular}{c|lcc} 
KARAKTERISTIK & \multicolumn{1}{c}{ FREKUENSI } & \% \\
\hline \multicolumn{1}{c}{ Usia } & $26-35$ Tahun & 16 & $43,4 \%$ \\
& $36-45$ Tahun & 10 & $33,3 \%$ \\
\multirow{5}{*}{ Jenis kelamin } & $46-50$ Tahun & 4 & $13,3 \%$ \\
\multirow{5}{*}{ Tingkat pendidikan } & Total & 30 & $100 \%$ \\
& Laki-laki & 13 & $43,3 \%$ \\
& Perempuan & 17 & $56,7 \%$ \\
& Total & 30 & $100 \%$ \\
& Sekolah Dasar & 12 & $40 \%$ \\
& Sekolah MenengahPertama & 9 & $30 \%$ \\
& Sekolah MenengahAtas & 8 & $26,7 \%$ \\
& & & $3,3 \%$ \\
& Perguruan Tinggi & 30 & $100 \%$
\end{tabular}

Tabel 1.1 menunjukkan bahwa mayoritas responden memiliki usia berkisar antara 26-35 tahun $(16 ; 43.4 \%)$, berjenis kelamin perempuan $(17 ; 56,7 \%)$ dan memiliki tingkat pendidikan terakhir sekolah dasar (SD) (12: 40\%). 


\section{b. Analisis Univariat}

1. Pengetahuan keluarga tentang faktor resiko penyebab stroke dapat dilihat pada tabel 1.2 di bawah ini.

Tabel 1.2 Distribusi frekuensi pengetahuan keluarga tentang faktor resiko penyebab stroke .

\begin{tabular}{llcc}
\hline No & Kategori Pengetahuan & Frekuensi (orang) & Presentase \\
\hline 1. & Baik & 4 & 13,33 \\
2. & Cukup & 10 & 33,33 \\
3. & Kurang & 16 & 53,34 \\
\hline & Jumlah & 30 & 100 \\
\hline
\end{tabular}

Berdasarkan tabel 1.2 tersebut dapat dilihat bahwa gambaran pengetahuan keluarga tentang faktor resiko yang dapat menyebabkan stroke terbanyak berada pada kategori kurang sebanyak 16 responden $(53,34 \%)$.

\section{Pengetahuan keluarga tentang gejala-gejala awal stroke}

Berdasarkan hasil penelitian maka didapatkan gambaran pengetahuan keluarga tentang gejala-gejala awal stroke.

Tabel 1.3 Distribusi frekuensi pengetahuan keluarga tentang gejala-gejala awal stroke

\begin{tabular}{llcc}
\hline No & Kategori Pengetahuan & Frekuensi (orang) & Presentase \\
\hline 1. & Baik & 13 & 43,33 \\
2. & Cukup & 15 & 50 \\
3. & Kurang & 2 & 6,67 \\
\hline & Jumlah & 30 & 100 \\
\hline
\end{tabular}

Berdasarkan tabel 1.3 tersebut dapat dilihat bahwa gambaran pengetahuan keluarga tentang gejala-gejala awal stroke terbanyak pada kategori cukup 15 responden (50\%).

\section{PEMBAHASAN}

Mayoritas responden pada penelitian tingkat pengetahuan tentang faktor resiko yang dapat menyebabkan stroke cenderung kurang. Hal ini diketahui dari jawaban kuesioner yang dibagikan dimana responden yang tidak mengetahui bahwa kesulitan tidur, riwayat keluarga dengan stroke, dan kadar hemoglobin yang tinggi dapat menjadi faktor resiko yang dapat menyebabkan stroke.

Kesulitan tidur merupakan salah satu faktor resiko yang dapat menyebabkan stroke (Junaidi, 2011), hal ini banyak tidak diketahui oleh responden. Kesulitan tidur menyebabkan tekanan darah tidak stabil yang dapat meningkatkan kekentalan darah sehingga pembuluh darah tidak lentur dan tersumbat hingga mengakibatkan resiko terkena stroke (Farida, 2009). Herman (2016) menyebutkan bahwa istirahat secara teratur memegang peranan penting dalam mengembalikan fungsi-fungsi otak termasuk kelenturan saraf yang sangat dibutuhkan dalam proses pemulihan stroke.

Hal lain yang tidak diketahui oleh responden terkait faktor resiko stroke yaitu riwayat keluarga dengan stroke. Para ahli kesehatan menyakini terdapat hubungan antara risiko stroke dengan faktor riwayat keluarga. Hasil ini serupa dengan penelitian oleh Maria. $\mathrm{N}$ (2018) yang menunjukan bahwa proporsi pasien stroke yang tidak memiliki riwayat penyakit pada keluarga lebih sedikit dibandingkan dengan pasien stroke yang memiliki riwayat penyakit keluarga. Artinya, sebagian besar pasien mendapatkan serangan stroke karena memiliki riwayat penyakit keluarga.

Temuan lainnya responden tidak mengetahui bahwa kadar hemoglobin yang tinggi juga menjadi faktor resiko stroke. Kadar hemoglobin yang tinggi menjadikan darah semakin kental. Seseorang yang 
mempunyai riwayat penyakit kolesterol tinggi berisiko mengalami pengentalan darah. Darah kental ini bisa meningkatkan risiko penyakit jantung, stroke dan gagal ginjal, tergantung seberapa kekentalan darah tersebut. Selain itu jawaban kuesioner yang paling banyak benar dijawab oleh responden pada faktor resiko yang dapat menyebabkan stroke yaitu kadar kolesterol lebih dari $200 \mathrm{mg} / \mathrm{dL}$. Mengkonsumsi daging atau makanan tingi lemak dengan kolesterol tinggi akan menyebabkan saluran pembuluh darah menjadi sempit sehingga mengganggu suplay darah ke otak yang menjadi salah satu faktor resiko penyebab stroke (Junaidi, 2011). Sedangkan cukupnya pengetahuan keluarga tentang faktor resiko yang dapat menyebabkan stroke dengan jumlah responden $10(33,33 \%)$ dapat disebabkan karena rendahnya pengetahuan pasien stroke tentang faktor resiko dan pencegahan sekunder penyakit ini menjadi masalah utama. Faktor risiko stroke meliputi atrial fibrilasi, hipertensi, dan diabetes mellitus (Zeng et al., 2012). Lebih lanjut, penelitian di New Zeland menunjukkan hanya $42,7 \%$ dari seluruh populasi penderita stroke yang mengetahui bahwa hipertensi adalah sebagai faktor risiko stroke (Bay et al., 2015). Pengetahuan pasien yang rendah tentang faktor risiko menjadi penyebab tidak taatnya pasien terhadap pengobatan (Hafsteinsdóttir, Vergunst, Lindeman, \& Schuurmans, 2011). Selain itu, kurang pengetahuan tentang tanda peringatan stroke juga menyebabkan pasien terlambat mencari pertolongan ketika mendapat serangan stroke. Seharusnya, pasien dengan faktor risiko stroke memiliki pengetahuan yang lebih baik agar dapat mencegah serangan stroke.

Pengetahuan keluarga tentang faktor resiko yang dapat menyebabkan stroke dengan kategori baik hanya dengan berjumlah 4 responden $(13,33 \%)$. Perbedaan ini karena responden pada tingkat penyerapan pengetahuan setiap individu dan dari segi tingkat pendidikan yang berbeda setiap individu. Hal ini sejalan dengan penelitian oleh Novida (2014) bahwa responden menurut tingkat pengetahuan faktor risiko stroke lebih banyak pada kategori baik. Sebesar 78,9\% pada kategori baik dalam mengetahui faktor- faktor apa saja yang termasuk risiko terkena penyakit stroke. Sisanya sebesar $21,1 \%$ pada kategori tidak baik dalam mengetahui faktor- faktor apa saja yang berisiko terkena penyakit stroke. Kesimpulan dari uraian diatas dapat dilihat bahwa keluarga pasien penderita stroke di RSUD. H. Boejasin Pelaihari memiliki pengetahuan yang rendah tentang faktor resiko stroke. Banyak dari keluarga yang menjadi responden menjawab kuesioner kurang tepat. Temuan ini sejalan dengan penelitian yang dilakukan oleh Handayani (2019) dengan hasil penelitiannya yang menunjukkan bahwa responden yang menjawab dengan benar sangat sedikit. Menurut peneliti pengetahuan tentang faktor risiko stroke sangat penting untuk meningkatkan kesadaran dalam rangka pencegahan stroke baik primer maupun sekunder sehingga individu mampu mengubah atau memodifikasi faktor risiko, dengan demikian akan menurunkan risiko stroke.

Mayoritas responden pada penelitian tingkat pengetahuan tentang gejala-gejala awal stroke cenderung cukup. Dimana jawaban kuesioner paling banyak benar itu pada gejala awal stroke yaitu salah satu sisi wajah ada yang tertarik/tidak simetris, nyeri kepala sampai muntah, rasa baal sesisi tubuh atau disekitar mulut, gerakan kaki/ tangan lumpuh, suara pelo, terjadi kehilangan keseimbangan saat berjalan, senyum mencong, sulit atau tidak dapat bicara, penglihatan pada salah satu mata atau keduanya mendadak buram, ketika makan/minum sering berceceran sesuai dengan teori Kemenkes RI 2019 dengan slogan Se-Ge-Ra-Ke-R-S. Sedangkan jawaban yang salah pada kuesioner yang dibagikan responden menyatakan bahwa kesulitan bernafas dan tiba-tiba nyeri pada salah satu tangan merupakan gejala-gejala awal stroke. Dua pertanyaan tersebut sebenarnya merupakan bentuk pertanyaan unfavorabel yang harusnya dijawab salah oleh responden yang mana kesulitan bernafas dan tiba-tiba nyeri pada salah satu tangan bukan merupakan gejalagejala awal stroke.

Rachmawati, dkk (2017) dalam penelitiannya mengungkapkan bahwa sebagian besar responden mempunyai skor pengetahuan yang cukup, ini disebabkan tingkat pendidikan responden sebagian besar berpendidikan sekolah dasar (SD) dan pemahamannya kurang baik. Hal ini berbeda dengan penelitian yang dilakukan oleh Semet, dkk (2016) dari hasil penelitian memiliki tingkat pengetahuan tanda dan gejala stroke yang baik. Menurut peneliti pengetahuan keluarga tentang gejala stroke sangat penting untuk mengenali gejala yang ada sehingga pasien segera diantar ke instalasi gawat darurat/rumah sakit dan mengurangi keterlambatan.

Tingkat pengetahuan tentang gejala-gejala awal stroke pada katagori baik dengan 13 responden $(43,33 \%)$. Berdasarkan data kuesioner sebagian besar responden telah mengetahui tanda dan gejala stroke. Paralisis maupun kelemahan di suatu sisi tubuh kejadian stroke adalah hal yang umum diketahui oleh masyarakat awam (American Heart Association, 2011). Penelitian ini sejalan dengan penelitian yang dilakukan oleh Anggraini (2010) yang menyatakan tingkat pengenalan gejala awal stroke termasuk dalam kategori baik.

Sedangkan tingkat pengetahuan gejala-gejala awal stroke pada katagori kurang 2 responden $(6,67 \%)$. 
Kurangnya pengetahuan dipengaruhi oleh kurangnya sumber informasi yang diterima oleh keluarga tentang stroke (Susanto, 2012). Informasi tentang faktor risiko, gejala serta penanganan awal stroke bisa didapatkan dari pelayan kesehatan, media sosial (internet, website, facebook, blog, pesan whatsapp dan twitter), maupun media masa (surat kabar, radio dan televisi). Namun pada kenyataannya sumber informasi tersebut masih jarang memberikan informasi tentang pengenalan gejala dan penanganan awal stroke. Pelayan kesehatan harus mengambil peran sebagai pemberi informasi (Handayani, 2019). Keberhasilan penanganan stroke akut dimulai dari pengetahuan keluarga bahwa stroke merupakan keadaan gawat darurat. Pendidikan kesehatan diarahkan untuk membantu keluarga melakukan perawatan diri serta bertanggung jawab terhadap kesehatan mereka sendiri dan keluarganya (Beal, 2015).

\section{Kesimpulan}

Tingkat pengetahuan keluarga tentang faktor resiko yang dapat menyebabkan stroke mayoritas dengan katagori kurang sebanyak 16 responden $(53,34 \%)$. Sedangkan pengetahuan keluarga tentang gejala-gejala awal stroke mayoritas dengan katagori cukup yaitu sebanyak 15 responden $(50 \%)$.

Penelitian ini menyarankan agar menjadi dasar bagi rumah sakit untuk meningkatkan peran dan kualitas dengan menerapkan sistem edukasi bagi keluarga baik saat pasien masuk ruang perawatan maupun sebelum pulang tentang stroke yang meliputi faktor resiko dan gejala awal stroke serta penanganan rehabilitas paska stroke.

\section{Acknowlegment}

Terima kasih kepada STIKES Suaka Insan yang sudah membantu memfasilitasi terwujudnya kegiatan penelitian ini.

\section{DAFTAR PUSTAKA}

Depkes RI, (2013). Badan Penelitian dan pengembangan Kesehatan Kementrian Kesehatan RI. Jakarta : Riset Kesehatan Dasar.

Oktovin, Nurachman Elly, Syafwani Muhammad (2020) Studi Fenomenologi Pengalaman Keluarga Suku Banjar Selama Merawat Anggota Keluarga Dengan Kondisi Stroke di Banjarmasin. Journal. Stikessuakainsan. Diakses $\quad 8 \quad$ Oktober 2020, dari http://garuda.ristekbrin.go.id/ documents /detail / 1732863

Harding and Bridgewater. (2010). Stroke scale you can use. Journal emergency nursing. 36 (1). Diakses 20 Oktober 2020 ,dari httphttp://journal. unipdu.ac.id:8080/ index.php/edunursing/article/view/1259

Goldszmidt, Adrian, R. Caplan, Louis. (2013). Stroke Esensial, edisi kedua. Jakarta: PT. Indeks

Arum, S. P. (2015). STROKE, Kenali, Cegah dan Obati. Yogyakarta: Notebook.

I

rfan, M (2012). Fisioterapi Bagi Insan Stroke.

Yogyakarta: Graha Ilmu

Widi N, S. Perhatikan ini pada penolongan pertama pasien stroke. Jurnal. Stikesperintis. Di akses 10 Oktober 2020, dari https://www.jurnal.stikesperintis.ac.id/ index.php/PSKP/article/view/335

Morton G. P. (2012), Kepe rawatan Kritis, Edisi 2, Jakarta: EGC

Wirawan N.\& Ida B.K. Putra. (2013). Prehospitalized Management On Acute Stroke. ejurnal medika udayana 694-709. vol. 2 no. 4. Diakses 11 Oktober 2020, dari http://www.core.acu.uk/download/pdf/29165763/pdf. Hariyanti, Tita, et al. (2015). Health Seeking Behavior. Jurnal Kedokteran Brawijaya 28 (3), 242-246, 2015. Diakses 13 Oktober 2020, dari http://.researchgate .net/publication/312249245

Notoatmodjo, S. (2012). Promosi Kesehatan dan Perilaku Kesehatan. Jakarta: PT Rineka Cipta

Junaidi, Iskandar. (2011). Stroke Waspadai Ancamannya. Yogyakarta: C.V. Andi Offset

Farida I dan Amalia. (2009). Mengantisipasi stroke. Yogyakarta. Bukubiru

Maria. N. (2018). Gambaran Faktor Yang Memperngaruhi Kejadian Stroke Iskemik Pada Masyarakat Di Kabupaten Timor Tengah Utara. Respository.Poltekeskupang. Diakses 10 Mei 2021 dari http://repository.

poltekeskupang.ac.id/1863/1/Maria\%20Noviati\%20Saun oah_KTI.pdf

Junaidi, Iskandar. (2011). Stroke Waspadai

Ancamannya. Yogyakarta: C.V. Andi Offset

Novida, dkk (2014). Faktor Yang Berhubungan Dengan Pengetahuan Tentang Stroke Pada Pekerja Institusi 
Jurnal Keperawatan Suaka Insan (JKSI) Vol. 6, No. 1, Juni 2021

Pendidikan Tinggi. Jurnal Berkala Epidemiologi, Volume 2 Nomor 1, Januari 2014, hlm. 13-23. Diakses 12 Juni 2021, dari http: file:///C:/Users/AR/ Downloads/149-1756-PB\%20(2).pdf

Handayani F. (2018) Pengetahuan Tentang Stroke, Faktor Risiko, Tanda Peringatan Stroke dan Respon Mencari Bantuan pada Pasien Stroke Iskemik. Semarang: Proceeding

Rachmawati et al. (2017) Pengetahuan Keluarga Berperan Terhadap Keterlambatan Kedatangan Pasien Stroke Iskemik Akut di Instalasi Gawat Darurat RSUD Ngudi Waluyo Wling. Journal unnes. Diakses 3 November 2020 ,

dari

https://jkb.ub.ac.id/index.php/jkb/article/view/1783

Semet, Prof R D GR, Kembuan MAHN, Karema W. (2016). Gambaran pengetahuan stroke pada penderita dan keluarga. Jurnal e-Clinic (eCl). Diakses 25 April 2021, dari

https://ejournal.unsrat.ac.id/index.php/eclinic/article/vie w/14560

American Heart Association. (2016). Ejection Fraction Heart Failure Measurement. Ahajournal. Diakses 13

Oktober 2020, dari http ://www. Strokeassociation .org

Anggraini, N. N., (2010). Deteksi Tingkat Pengenalan Gejala Awal Stroke dan Pengetahuan Cara Penanganan Stroke Pada Masyarakat. Skripsi. Surabaya Universitas Airlangga. Diakses 13 Juni 2021, dari http: file:///C:/Users/AR/ Downloads/149-175-6PB\%20(2).pdf 